\title{
Slovenia: difficulties and strengths of psychiatric research in a small country
}

MOJCA Z. DERNOVSEK and ROK TAVCAR

With a population of nearly 2000000 and an area of about $20000 \mathrm{~km}^{2}$, Slovenia is a heterogeneous European country that extends from the Mediterranean Sea to the Alps. Slovenian political history dates back to the 6th century, when the first free principality of the ancient Slovenians was established - Caranthania - famous for its democratic institutions, legal system, popular elections of dukes and progressive legal rights for women. From the 13th century until 1918, Slovenians were ruled by the Habsburgs. After 1918, Slovenia became a part of Yugoslavia and again enjoyed a considerable degree of autonomy. But as the political and economic crisis of Yugoslavia worsened, at the plebiscite in December $199087 \%$ of the voting population voted in favour of sovereignty. Thus, Slovenia declared its independence on 25 June 1991, and became a member of the United Nations in May 1992. Until the Second World War the psychiatric tradition in Slovenia was German. Afterwards, the AngloSaxon tradition has gradually entered Slovene psychiatry.

Doing research in a small country like Slovenia, which is additionally in transition from a socialist to a liberal capitalist system, has its own characteristics, which may seem somewhat peculiar to an external observer. The main problem is that research resources are limited. This applies not only to financial resources but even more so to personnel. The number of researchers is relatively low and these usually cannot specialise in only one research field. They have to deal with several research projects, which are often barely related to each other. This dissipation of research energy in numerous projects is clearly a disadvantage since it is not easy to follow the current scientific literature in a number of fields. Therefore, researchers have to invest much greater efforts in preparing research proposals and conducting the projects. The same applies to other activities, such as teaching, supervising younger researchers, reviewing national research proposals and papers. Because of the shortage of personnel there are almost no fulltime researchers in psychiatry. Researchers have to do clinical work to the same extent as other non-research-oriented mental health professionals.

On the other hand, there are also some advantages of working in a small country. One of them is the possibility of almost complete follow-up of patients. There are only six psychiatric hospitals, which are unevenly located in different geographical areas, and most clinical staff know at least one of the clinical team in the other hospitals. Therefore, exchange of information is usually very good, including the acquisition of copies of medical records from other institutions in order to complete a follow-up.

\section{WORK PERFORMED AND ONGOING}

Our research group at the University Psychiatric Hospital in Ljubljana is the leading scientific group in clinical psychiatry in Slovenia. Being well connected with the Institute of Public Health of the Republic of Slovenia in terms of projects and shared staff, we also cover the increasingly important field of public mental health. In other words, our work and plans are highly representative of what is going on in psychiatric research in Slovenia.

In the past 10 years the group has been mainly dealing with research into suicidal behaviour and other public mental health indicators, psychiatric services research, neuropsychological and neurocognitive studies, management of violence and other clinical studies.

\section{Psychiatric services research}

This research has quite an extensive background and is a clear example of a multidimensional approach. One of the first studies investigated the rehospitalisation rate in schizophrenia, which was comparable to that in other countries (around $25 \%$ per year) despite large differences in the organisation of health care (Tavcar \& Dernovsek, 1997). Another study explored the prescription of antipsychotics for in-patients with schizophrenia. The authors built two multivariate models with predictors of prescribing depot $v$. oral typical antipsychotics and atypical $v$. typical antipsychotics (Tavcar et al, 2000). The research group also studied predictors of compliance in schizophrenia and challenged the popular belief that non-compliance is associated with the unpleasant (mostly extrapyramidal) adverse effects of typical antipsychotics (Novak-Grubic \& Tavcar, 2002). A very thorough 1-year follow-up study explored the quality of life and treatment costs in patients with schizophrenia treated with depot antipsychotics (Dernovsek et al, 2001). The study showed that the 'older' depot antipsychotics still have their role in treatment (with relatively low rehospitalisation rates) and that medication costs are only a minor part of treatment costs (rehospitalisations of only $15 \%$ of patients accounted for almost $50 \%$ of all costs).

\section{Use of seclusion and restraint in the management of violence}

This is a newer research field, which only recently attracted more attention, but we are proud of the way it has been carried out, which enabled immediate and extensive clinical utilisation of the research findings. First, the problem was identified by clinical staff, then the researchers investigated it in detail and finally national guidelines were drawn up according to research findings and the current literature (Tavcar et al, 2002). In this case, very good cooperation was established with the European Violence in Psychiatry Research Group and some results were presented at major international meetings.

\section{Neuropsychological and neurocognitive studies}

A significant contribution of our research group to this evolving field was presented in one research paper, which attracted more than 20 citations and is believed to be one of the fundamental studies on cognitive processes in schizophrenia (Mlakar et al, 1994). Current research in this field is directed towards further exploration of cognitive functions (meta-representations of various hierarchies) and the origins of 
negative symptoms in schizophrenia. Our future goal is to develop and standardise a clinically useful instrument for delineating primary and secondary negative syndromes in schizophrenia.

\section{Suicidal behaviour}

Since Slovenia has had a very high suicide rate (around 30 per 100000 inhabitants per year) for decades, it is not surprising that there is a long tradition of suicidology research. One of the first and most complete suicide registries in Europe was established more than 30 years ago by Professor Milcinski, who did a lot of epidemiological work in this field. Because of changes in legislation (increased data protection standards limit obtaining the relevant data) the importance of the Slovene suicide registry has diminished over the past 5 years. This has led to a shift in suicide research towards more specific and well-defined questions. One of them is research on inpatient suicides, which resulted in two frequently cited publications. The first paper (Steblaj et al, 1999) reports the predictors of in-patient suicide, with special attention to unrecognised depression in patients with schizophrenia. The other report (Marusic et al, 2002) investigated the differences between in-patient suicides and suicides in the community. Other studies dealt with suicides in some specific groups, such as the young and the elderly (Marusic et al, 2003), and among patients with alcoholrelated mental disorders.

Since our group is affiliated with a tertiary psychiatric hospital, we have access to the most complicated cases of mental disorder. In addition, our hospital is the only Slovene institution with legal authorisation for off-label use of psychotropic medication and clinical trials of nonlicensed drugs. From this clinical material several unusual case reports have been

MOJCA Z. DERNOVSEK, MD, PhD, University Psychiatric Hospital, Ljubljana-Polje and Institute of Public Health of Republic of Slovenia, Ljubljana; ROK TAVCAR, MD, PhD, University Psychiatric Hospital, Ljubljana, Slovenia

Correspondence: Dr Rok Tavcar, University Psychiatric Hospital, Studenec 48, SI-1260 Ljubljana-Polje, Slovenia. Tel: +386 I 5872 312; Fax: +386 I 5284 618; e-mail: rok.tavcar@mf.uni-lj.si

published in the national and international scientific literature (Dernovsek \& Tavcar, 1997). In a way, this is our contribution to the permanent education of psychiatrists.

\section{NEW INITIATIVES \\ AND CHALLENGES FOR THE FUTURE}

In future, several new projects will start. A neuroimaging study is aiming to elucidate the importance of suspected minor brain damage for impulsivity and suicidal behaviour in patients with alcohol dependence. In the field of violence research, three current multi-disciplinary studies are ongoing, one of them sponsored by the Slovene Ministry of Education, Science and Sports. Furthermore, Slovenia was appointed host of the spring 2003 meeting of the European Violence in Psychiatry Research Group. This meeting will further improve implementation of research results in practice. To share results and experiences in the above-mentioned research fields we would like to invite and encourage international researchers to mutually beneficial collaborations.

\section{CONCLUSIONS}

The Slovene experience shows that research is important also in small communities because it further develops the skills of health care professionals, serves as a motivation for updating their knowledge, enhances contacts and prevents the type of nihilism that may arise from comparisons with different, more developed countries.

\section{REFERENCES}

Dernovsek, Z. \& Tavcar, R. (1997) Risperidoneinduced leucopenia and neutropenia (letter). British Journal of Psychiatry, 17I, 393-394.

Dernovsek, M. Z., Prevolnik-Rupel, V., Rebolj, M., et al (200I) Quality of life and treatment costs in schizophrenic outpatients, treated with depot neuroleptics. European Psychiatry, 16, 474-482.

Marusic, A., Tavcar, R., Dernovsek, M., et al (2002) Comparison of psychiatric inpatient suicides with suicides completed in the surrounding community. Nordic Journal of Psychiatry, 56, 335-338.

_ , Landau, S. \& Tomori, M. (2003) Long-term trends, seasonality, weekly distribution, and methods of suicide in Slovenia: comparison between the younger and older population. Archives of Suicide Research, 7 , 135-143.

Mlakar, J., Jensterle, J. \& Frith, C. D. (1994) Centra monitoring deficiency and schizophrenic symptoms. Psychological Medicine, 24, 557-564.

Novak-Grubic, V. \& Tavcar, R. (2002) Predictors of noncompliance in males with first-episode schizophrenia, schizophreniform and schizoaffective disorder. European Psychiatry, I7, 148-154.

Steblaj, A., Tavcar, R. \& Dernovsek, M. Z. (1999) Predictors of suicide in psychiatric hospital. Acta Psychiatrica Scandinavica, 100, 383-388.

Tavcar, R. \& Dernovsek, M. Z. (1997) Recidivism in Slovenia. Psychiatric Services, 48, 955-956.

\& Zvan, V. (2000) Choosing antipsychotic maintenance therapy. A naturalistic study. Pharmacopsychiatry, 33, 66-70.

, Novak-Grubic, V., et al (2002) Slovenian guidelines for management of violence in psychiatric hospitals. In Management Strategies and Guidelines (edsT. Palmstierna \& G. Nyman), pp. 5-10. Stockholm:

Prevention and Treatment of Aggression. 